Tables of Partitions

Initiated and Computed by Hansraj Gupta. Computed Independently by C. E. Gwyther and J. C. P. Miller. (Royal Society Mathematical Tables, Vol. 4.) Pp. xxxix +132. (Cambridge: At the University Press, 1958. Published for the Royal Society.) $63 s$. net.

HIS is undoubtedly the most comprehensive tables of partitions ever published. The principal function tabulated is $p(n, m)$, the number of partitions of the positive integer $n$ into at most $m$ integral parts (or into integral parts none of which exceeds $m$ ). Table 1 , occupying 87 pages, gives $p(n, m)$ for $n=1(1) 200, m=0(1) \min (n, 100)$ and for $n=200(1) 400, m=0(1) 50$. Table 2, of 32 pages, is intended for use as an auxiliary table, by means of which $p(n, m)$ can be calculated readily for values of $m$ not given in Table 1. It gives values of $p_{2}(n, m)$ for $n \leqslant 1,000$, the maximum value of $m$ varying from $n$ for $n \leqslant 50$ to 0 for $500 \leqslant n \leqslant 1,000$. Here $p_{2}(n, m)$ is the number of partitions of $n$ into parts consisting of two varieties of integers not exceeding $m$ and one variety of each larger integer; in particular, $p_{2}(n, 0)=p(n)$, the number of unrestricted partitions of $n$. A third table, of ten pages, tabulates a range of values of $p_{3}(n, m)$, the number of partitions of $n$ into parts consisting of three varieties of integers not exceeding $m$ and two varieties of each larger integer. The range is $n=1(1) 50, m=0(1) n$; $n=50(1) 100, m=0(1) 19 ; \quad n=100(1) 150, \quad m=0(1) 6$; and $n=150(1) 200, m=0$. The final tables gives $p_{4}(n, 0)=p_{3}(n, n)$ for $n=1(1) 200$.

The introduction gives an interesting review of the extensive literature on these functions, and in particular of explicit formulæ for $p(n, m)$ as function of $n$ for fixed $m(m \leq 12)$. It concludes with a description of the method of construction of the tables, in which, in the fourth line from the foot of p. xxxiv, $p_{1}(n)=p_{2}(n, 0)$ should read $p_{2}(n)=p_{3}(n, 0)$.

The rather tricky problems of layout in a table of double entry involving large numbers have been ingeniously overcome, and the tables should be easy to refer to.

J. A. ToDd

\section{Set Theory}

By Felix Hausdorff. Translated from the German by John R. Aumann et al. Pp. 352. (New York: Chelsea Publishing Company, 1957.) 6 doilars.

TAUSDORFF's famous work, "Grundzüge der 1 Mengenlehre" (Leipzig, 1914), needs no introduction to the pure mathematician. In the third edition the first nine chapters are an almost unchanged reprint of the second edition. A tenth chapter has been added, dealing with the Baire condition for sets and for functions, the restricted Baire condition, and with half-schlicht mappings. This is a valuable and interesting addition.

\section{R. G. CookE}

\section{Linear Programming and Economic Analysis}

By Prof. Robert Dorfman, Prof. A. Samuelson and Prof. Robert M. Solow. (The Rand Series.) Pp. ix +527 . (London: McGraw-Hill Publishing Company, 1958.) $77 s .6 d$.

THIS book is one of the series presenting the results of research by the Rand Corporation. It is intended for economists who wish to learn something of recent developments in the application of mathematics to economics. The first few chapters present the method of linear programming, with some applications worked out in detail, and the special methods available for transportation problems. There is a chapter on non-linear programming and two chapters on input-output analysis as developed by Leontief. Other chapters deal with dynamic aspects of linear models and with programmes for capital accumulation. An essential idea here is optimization over time. Linear programming is discussed in relation to the theory of general equilibrium and to welfare economics. Finally, there are chapters on the theory of games and its relation to linear programming. These last chapters are added for the sake of completeness, and this is the only justification, for, as the authors point out, ". . . the 13 years that have elapsed since the publication of the "Theory of Games" (by von Neumann and Morgenstern) have seen no important applications of game theory to concrete economic problems".

The reader should find the book easy going, for the exposition is nowhere concentrated and the impression is that the authors have been allowed as many pages as they desired. This allows detailed explanation and the inclusion of many fully worked examples. But it also makes the book expensive and it means that the reader will have to spend a long time absorbing relatively little. The reviewer feels that the rate of communication between the authors and the reader will be too slow to be very satisfying. It might have been better to have said as much in fewer words. $\quad$ L. S. GODDARD

\section{Salmonellosis in Animals}

By Dr. A. Buxton. (Review Series No. 5 of the Commonwealth Bureau of Animal Health.) Pp. vii +209 . (Famham Royal: Commonwealth Agricultural Bureaux, 1957.) 25s.

$$
\text { Tr }
$$

HIS book is a review of salmonellosis in animals, and, in particular, of the vast literature which has accumulated from 1888 to the present day on the many aspects of this subject. The author has been careful to include information from field studies and the natural history of disease as well as from the laboratory and the experimental work; he has interpreted these in relation to the naturally occurring disease.

A chapter is devoted to technical methods of classification of the Salmonella group of organisms, of which more than 500 have been described. Reference is made to certain details of antigenic structure, their possible relationship to virulence, and the effect which certain minor variations in the structure of the organisms have had on the detection of infection in the field.

The distribution of Salmonella serotypes among the various animals, birds, reptiles, insects, and ticks, summarizes our present knowledge. The epidemiology is well covered; obviously the author has been personally concerned with this aspect. Careful consideration is given to general aspects such as the state of the host, its diet and environment and the influence such factors exert on clinical infection.

Many problems remain unsolved in the animal disease; as yet there is no final proof of the value of vaccines or of antibacterial substances. The author is to be congratulated on bringing into one book so much information, previously available only in scientific journale; also for including data on wild and unusual animals so often neglected in the text-books. JOAN TAYLOR 